\title{
BMJ Open Workforce crisis in primary healthcare worldwide: Hungarian example in a longitudinal follow-up study
}

\author{
Magor Papp, ${ }^{1}$ László Körösi, ${ }^{2}$ János Sándor, ${ }^{3}$ Csilla Nagy, ${ }^{4}$ Attila Juhász, ${ }^{4}$ \\ Róza Ádány, ${ }^{3,5}$
}

To cite: Papp M, Körösi L, Sándor J, et al. Workforce crisis in primary healthcare worldwide: Hungarian example in a longitudinal follow-up study. BMJ Open 2019;9:e024957. doi:10.1136/ bmjopen-2018-024957

- Prepublication history for this paper is available online. To view these files please visit the journal online (http://dx.doi org/10.1136/bmjopen-2018024957).

Received 3 July 2018 Revised 1 July 2019 Accepted 2 July 2019

Check for updates

(c) Author(s) (or their employer(s)) 2019. Re-use permitted under CC BY-NC. No commercial re-use. See rights and permissions. Published by BMJ.

${ }^{1}$ National Public Health Institute, Budapest, Hungary

${ }^{2}$ National Institute of Health Insurance Fund Management,

Budapest, Hungary

${ }^{3}$ Department of Preventive Medicine, Faculty of Public Health, University of Debrecen, Debrecen, Hungary

${ }^{4}$ Public Health Administration

Service of Government Office of Capital City Budapest, Budapest, Hungary

${ }^{5}$ MTA-DE Public Health Research Group of the Hungarian Academy of Sciences, University of Debrecen, Debrecen, Hungary

Correspondence to

Dr Róza Ádány;

adany.roza@sph.unideb.hu

\section{ABSTRACT}

Objective The study was designed to explore the development of the general practitioner (GP) shortage in primary care and its characteristics in Hungary. Design Longitudinal follow-up study over the decade 2007-2016.

Methods Analyses were performed on changes in number, age and sex of GPs by practice type (adult, paediatric and mixed), as well as on their geographical distribution and migration between areas characterised by deprivation index (DI) at municipality level. The association between deprivation and vacancy for GPs was studied by risk analysis. The number of population underserved was defined by DI quintile.

Setting and subjects The study involved all general practices and GPs in the period examined.

Main outcome measure It is showed that the number of general practices with unfilled GP posts was increasing exponentially, mainly in the most deprived areas of the country.

Results A decrease in the number of GPs in all types of practices, especially in mixed (by $7.7 \% ; p<0.001$ ) and paediatric (by $6.5 \%$; $p<0.001$ ) ones, was shown; the number of adult practices with unfilled GP posts doubled, while the number of paediatric practices with a vacancy for a paediatrician more than tripled. The average age of GPs was increased by 3.7 years $(p<0.001)$ in adult, by 5.4 years $(p<0.001)$ in paediatric and by 4.2 years $(p<0.001)$ in mixed practices. In 2007, $52.27 \%(95 \%$ Cl 51.03 to 53.5) of the GPs were women, and this rate increased to $56.19 \%$ (95\% $\mathrm{Cl} 54.93$ to 57.44 ) by the end of the decade. An exponential association between relative vacancy rate and deprivation was confirmed. As a result of the migration of GPs, in the most deprived areas, the number of GPs decreased by $8.43 \%$ (95\% Cl 5.86 to 10.99).

Conclusions The workforce crisis in Hungarian primary care is progressively deepening and resulting in more severe inequity in access to healthcare.

\section{INTRODUCTION}

The workforce crisis in primary care (PC) is a worldwide phenomenon. The shortage in general practitioners (GPs) is particularly severe in low-income and middle-income countries in Africa, Asia and the Pacific, ${ }^{1-3}$ but it is becoming more striking in high-income

\section{Strengths and limitations of this study}

The study is based on a comprehensive longitudinal follow-up survey at a national level to evaluate major changes in the number and distribution of general practitioners (GPs)

- The survey used an area-based composite indicator to study the relationship between deprivation and shortage in GPs in the country.

- The study analysed the migration of GPs between practices, but the reasons for leaving primary care were not investigated in detail.

- Data were available for the first day of each year; thus, the study could not detect transient changes in a year.

countries as in the USA, ${ }^{45} \mathrm{UK}^{6-8}$ and Switzerland $^{910}$ as well. In 2016, England was already approximately 6500 GPs below the ideal number, and this gap would increase to 12100 by $2020 .{ }^{6}$ Switzerland is also facing an impending $\mathrm{PC}$ workforce crisis since almost half of all PC physicians are expected to retire in the next decade. ${ }^{9} 10$ As the "Health at a glance, 2016' report ${ }^{11}$ shows in the Organisation for Economic Co-operation and Development (OECD) countries-among them in the European Union member states-the workforce crisis at the level of PC is so deep that in the period of 2011-2013 a significant portion of the emergency department (ED) visits occurred because PC was not available. In certain Central Eastern European (CEE) countries (Czech Republic, Slovakia), this proportion of ED visits was as high as $52 \%-74 \%$.

The shortage of GPs seems to be the key issue of the workforce crisis in PC throughout the world which may strongly contribute to the limited access of people living in socioeconomically deprived conditions to PC and other health services. ${ }^{12}$ The Position Paper of the Irish Medical Organisation on health inequalities denotes that vulnerable rural and 
deprived urban communities have no adequate GP cover in Ireland. ${ }^{13}$ Demographic studies identified a shortage of PC service providers located in the countryside and a relative oversupply in metropolitan areas in Germany, and in German cities with a population size of more than 500000 the distribution patterns of GPs were significantly correlated with the geodemographic index, an area measure of deprivation. ${ }^{14}$ Although the Royal College of General Practitioners reported that the so-called 'underdoctored' areas are the most-deprived regions of the UK, that is, 'the general practice workforce is unevenly spread across the country, with the fewest doctors in the most-deprived areas, exacerbating health inequalities', ${ }^{15}$ it is worth mentioning that there was a substantial reduction in socioeconomic inequality in family physician supply associated with national policy for establishing new practices in the most deprived areas under the 'Equitable Access to Primary Medical Care (EAPMC) ' programme. ${ }^{16}$

Substantial geographical inequalities in family physician supply was demonstrated between large subnational areas even in high-income countries with universal health coverage. However, because these studies have focused on large areas, they have not been able to accurately describe socioeconomic inequality in PC supply by pinpointing PC shortages in specific disadvantaged neighbourhoods. ${ }^{17-26}$

WHO Department of Human Resources for Health provided an overview on the inequitable access of populations to PC. The underserved populations were identified in remote and rural areas where the socioeconomic environment, such as working and living conditions, as well as access to education for children were unfavourable. ${ }^{27} 28$ Data are available almost exclusively from cross-sectional rather than longitudinal surveys ${ }^{629-31}$; therefore, these studies are unable to report on previous and actual translations in the PC system. In addition, these surveys were conducted among GPs typically in a single region of a country, ${ }^{30-32}$ which may not be entirely typical of a country as a whole.

Concerning the population size of Hungary, as well as the fact that the workforce crisis in PC was evolving in the last decade the country may serve as an ideal field to a study targeting the characterisation of the workforce crisis in its development. In Hungary, responsibilities for PC have been centralised at national level and the only source of financing is the National Health Insurance Fund. The local governments are responsible for ensuring that PC services are available to their population, so practices are organised by them at municipality level. The size of the practices, reflecting the number of clients served, varies widely (800-3000 persons/practice), and the average size is approximately 1550 persons/practice. Generally, more family practices operate in more highly populated municipalities, whereas one family practitioner serves more than one municipality in less populated areas. PC physicians are mostly $(95 \%)$ self-employed service providers contracted to the National Health Insurance Fund, and they work almost exclusively in solo practices, that is, one GP-with the assistance of one practice nurse-serves the clients. GPs provide a complexity of care (screening, health status assessment, diagnosis, treatment, follow-up and referral to the secondary level of care) through capitation-based insurance coverage for this basic healthcare service. Concerning the type of practices, about half of them serves only adults, one quarter of them serves exclusively children, while the remaining are mixed practices. If a GP post becomes vacant, it is very difficult to recruit replacement GP, in general GPs from the nearby practices as locum tenents provide services in very limited working hours, so the population belonging to the practice with vacant GP post will be definitively underserved. Theoretically, for GPs, there are some competitive work opportunities, because about $40 \%$ of them in addition to specialisation in family care have medical specialisation in paediatrics or internal medicine, but the healthcare institutions at secondary or tertiary levels rarely provide GPs with positions, so they can work almost exclusively in the emergency service at PC level. On the basis of the results obtained in the Hungarian Public Health Focused Primary Care Model Programme, ${ }^{36-39}$ the government started to disseminate the GPs' cluster work in a new pilot programme in 2018. GPs' clusters are built on the cooperation of six GPs employing health professionals (public health professionals, community nurses, physiotherapists, dieticians, health psychologists) who-in addition to the traditional patient care-are competent to plan and implement various public health services at cluster level. In 2019, approximately $6 \%$ of the PC practices is involved in this pilot, that is, solo practice is still the norm in Hungary. On the basis of the three dimensions of PC structure-governance, economic conditions and workforce development-the Hungarian PC system is qualified into the medium category, ${ }^{40}$ but the coordination and comprehensiveness are found to be weak. ${ }^{18}$

Our study is designed to follow the development of the GP shortage and to describe the characteristics of changes in Hungary, a country which illustrates a prime example of CEE countries with a workforce crisis in PC. The secular trend by changes in the number, age and sex of GPs by type of practices, as well as the distribution of GPs and vacant GP positions by deprivation is characterised in a longitudinal follow-up design in the 10-year period that began on 1 January 2007 and ended on 1 January 2017.

\section{METHODS}

\section{Data on general practices analysed}

The analysis is based on data provided by the National Institute of Health Insurance Fund Management (NIHIFM) for the period of 1 January 2007 to January 2017 in Hungary. The NIHIFM provided detailed information for the first day of each year on the number, type (adult, paediatric or mixed) and geographical (municipal) location of general practices, identified by numeric practice codes. It was reported whether the GP post of the practice was filled or unfilled on the first day of each year. In the case of practices with filled GP posts, the age and 
sex of the GPs were registered. If the GP post was unfilled, the period during which there was an inability to recruit GP, as well as the number of population underserved (ie, the number of people belonging to practice with vacant GP post) was also indicated. If the reason for vacancy involved moving a GP from one PC practice to another, the deprivation status of the municipalities where the former and the newly engaged practices were found was also considered in the analysis; the number of practices affected was defined by deprivation index (DI) quintiles.

In the analysis performed, the change in the number of practices with filled and unfilled GP posts and the change in the average age of GPs were defined by the type of practices for the period investigated. In addition, the change in distribution by sex was also determined.

\section{Deprivation}

To see the relationship between the distribution of unfilled practices and the socioeconomical status (SES) of the settlements where the practices are located, association analyses were carried out. The SES was characterised by the DI, an area-based composite indicator at the municipality level. The DI was built from seven different indicators (income, the level of education, the rate of unemployment, the rate of one-parent families, the rate of large families, the density of housing and car ownership) derived from the Regional Informational System of the Ministry of Local Government and Regional Development. The data were originally obtained from the Hungarian Central Statistical Office (from the Census 2011) and the Hungarian Tax and Financial Control Administration (for the year of the census). The development of the DI was carried out by using principal component analysis. All variables were first transformed by using the natural log-transformation and then standardised. Areas with positive (higher) index values were municipalities with a lower socioeconomic status than the national average, and the converse was shown in areas with negative (lower) index values. This method to calculate DI values has been published previously by us ${ }^{41}$ and successfully used in several studies. ${ }^{42-45}$ The same or similar approaches measuring SES were also applied in studies carried out in other countries all over Europe ${ }^{46}$ such as the UK, ${ }^{47-50}$ France, ${ }^{51}$ Spain, ${ }^{52}{ }^{53}$ Germany, ${ }^{54}$ Denmark,${ }^{55}$ Switzerland, ${ }^{56}$ Italy, ${ }^{57}$ Czech Republic ${ }^{58}$ and Slovenia. ${ }^{59}$

\section{Mapping and risk analysis of vacancy}

A hierarchical Bayesian binomial model was used to predict the relative vacancy ratio at the municipality level. The data consisted of the observed number of practices with unfilled GP posts and total number of practices for each municipality. The convolution model, originally proposed by Besag et al, ${ }^{60}$ was used and incorporates both a heterogeneous and spatially structured random effect. The parameters for the spatial model were estimated via Integrated Nested Laplace Approximations (INLA) directly in $\mathrm{R}$ using the package INLA. ${ }^{6162}$ The map for vacancy shows the relative vacancy rate and exceedance posterior probabilities.

Using the risk analysis capabilities of the Rapid Inquiry Facility, ${ }^{63}$ the association between deprivation and vacancy for GPs was calculated. Relative frequencies of vacancy in relation to the national average were calculated by DI quintiles as a municipality-based categorical covariate. $\chi^{2}$ tests for homogeneity and for linear trend were also carried out to test the global association of the DI and the vacancy.

\section{Patient and public involvement}

Patients and or public were not involved.

\section{RESULTS}

The number of local administrative units 2, called municipalities or settlements in Hungary, was 3176 with a total population number decreasing from 10066158 (2007) to 9797561 (2017) in the period examined.

At the beginning of the decade covered by the study, there were 6427 PC practices serving the country's population, and at the end of the period, 6350 practices were operating. During the survey period, the number of practices decreased by 77 . Behind the change in the number of practices were decisions made by local governments having the right to merge practices that typically could not be fulfilled for years in small-sized settlements with other practices belonging to the same administrative municipality.

\section{Change in number of practices with unfilled GP posts}

In Hungary, the number of GPs in the beginning of the decade examined was 6247 . Of these, $53.2 \%$ served adults, $24.3 \%$ served children exclusively and the remaining $22.5 \%$ served mixed practices. For the end of the period, 6003 GPs were registered with the following distribution: $54.6 \%$ in adult practices, $23.8 \%$ in paediatric practices and $21.6 \%$ in mixed practices (table 1 ).

The number of GPs in all types of practices decreased during the decade, especially the number of GPs in mixed (by $7.7 \%$ ) and paediatric (by 6.5\%) practices. Despite the administrative measures resulting in a reduction of the number of practices, the number of practices with a vacant GP post increased dramatically, especially in the second half of the period examined. At the beginning of the decade, the number of practices with unfilled GP posts was 180 , while at the end of the period it was 347 ; these shifts occurred across 519 settlements. By the end of the decade, the number of adult practices with unfilled GP posts doubled, while the number of paediatric practices with a vacancy for a paediatrician more than tripled. Although the relative change in the case of vacant mixed practices was less $(68.1 \%$ increase), at the end of the decade among the practices with a vacant GP post this type of practice was dominated (adult: $24.8 \%$, paediatric: $20.5 \%$, mixed: $54.7 \%$ ), as at the beginning of the period (adult: $25.0 \%$, paediatric: $12.2 \%$, mixed: $62.8 \%$ ). The 


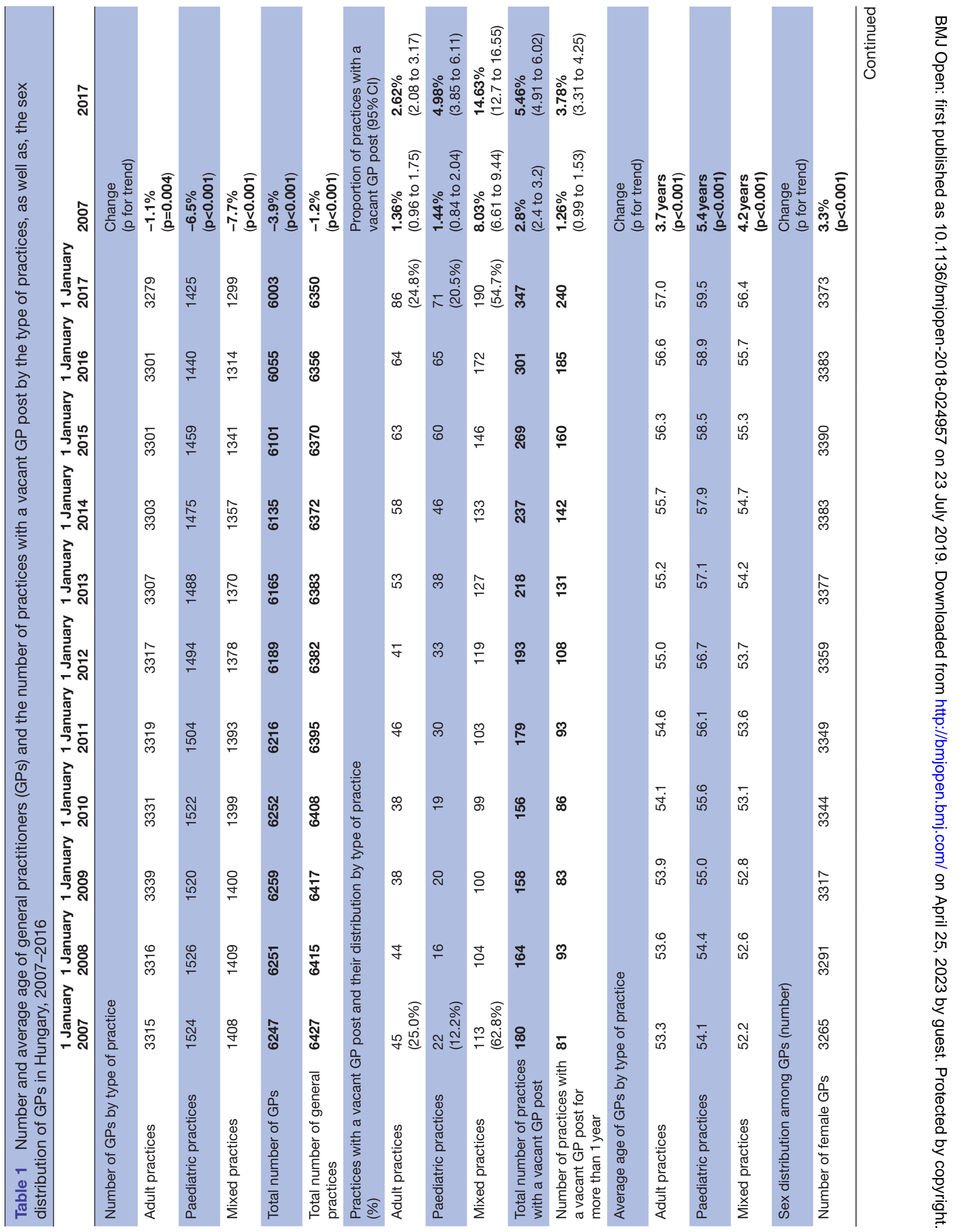




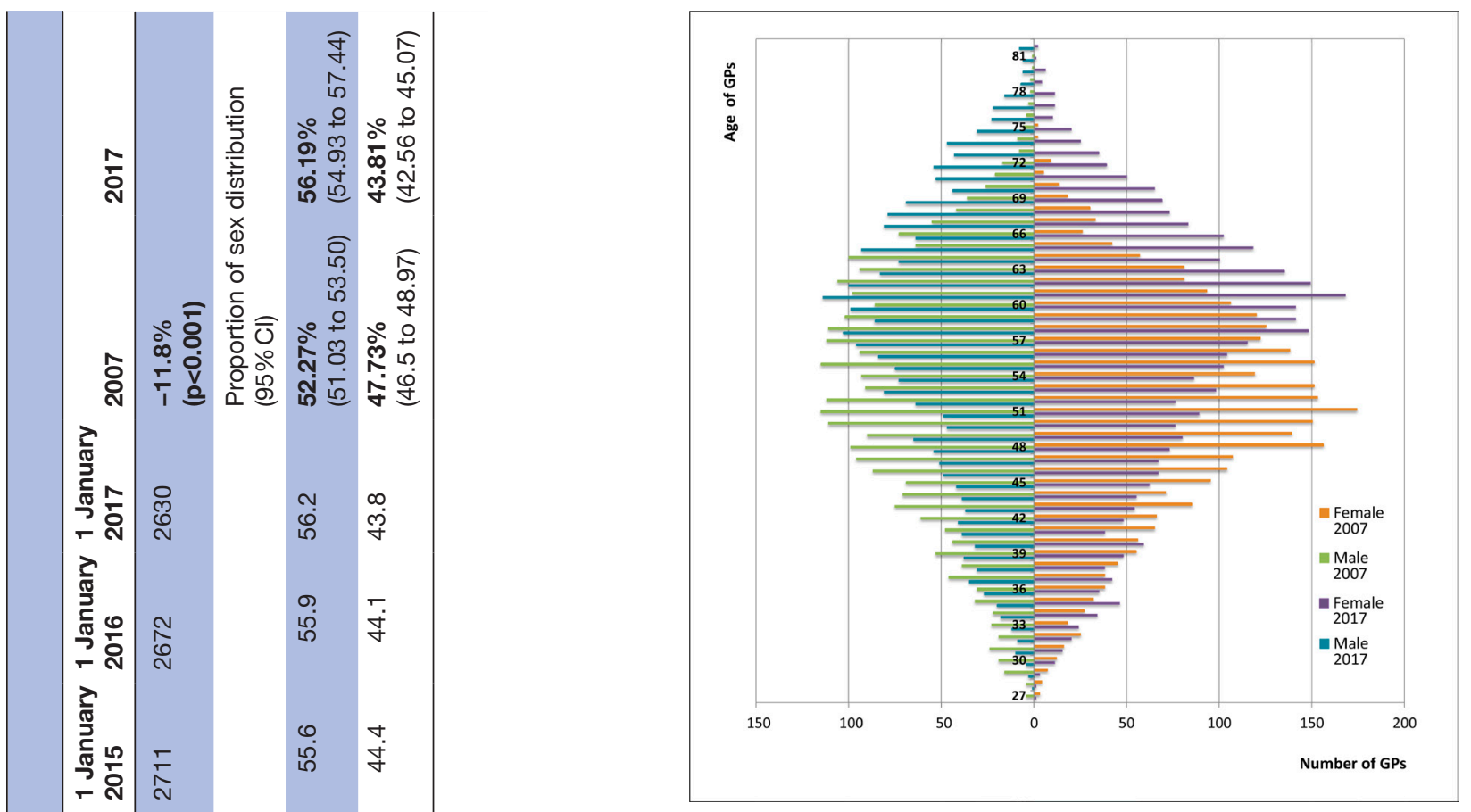

Figure 1 The age and sex distribution of general practitioners (GPs) in 2007 and 2017 in Hungary.

most serious findings were that $69.2 \%$ of the practices with a vacancy for GP in 2017 had had the vacancy for more than a year, and that number was three times higher than it was in 2007 (240 vs 81).

\section{Change in age and sex distribution of GPs}

The average age of GPs was high even at the beginning of the decade, especially the age of the paediatricians (54.1 years), but the average age of GPs serving adult and mixed practices was also over 50 years ( 53.3 and 52.2 years, respectively). During the decade examined, the average age of GPs was increased by 3.7 years in adults, by 5.4 years in paediatric and by 4.2 years in mixed practices (table 1 ). Concerning the balance by sex, in 2007, $52.3 \%$ of the GPs were women, and this rate increased to $56.2 \%$ by the end of the decade. The age structure graph showing the distribution of female and male GPs by age in 2007 and 10 years later in 2017 (figure 1) clearly indicates both ageing and feminisation of the GPs population.

\section{Association between deprivation and practices with an unfilled GP post}

Mapping the DI values shows that the most-deprived areas were found in the north-eastern and south-western parts of Hungary. The least deprived sections were areas in the north-western part of the country and in the capital city of Budapest and its neighbouring areas (figure 2A). The areas with the highest relative vacancy rates were found along the north-eastern border of Hungary and in the mid-eastern and south-western parts of the country (figure 2B). Maps for DI and practices with vacant GP posts show remarkable overlap; the resultant pattern of excess vacancy rates showed a correlation with a spatial 


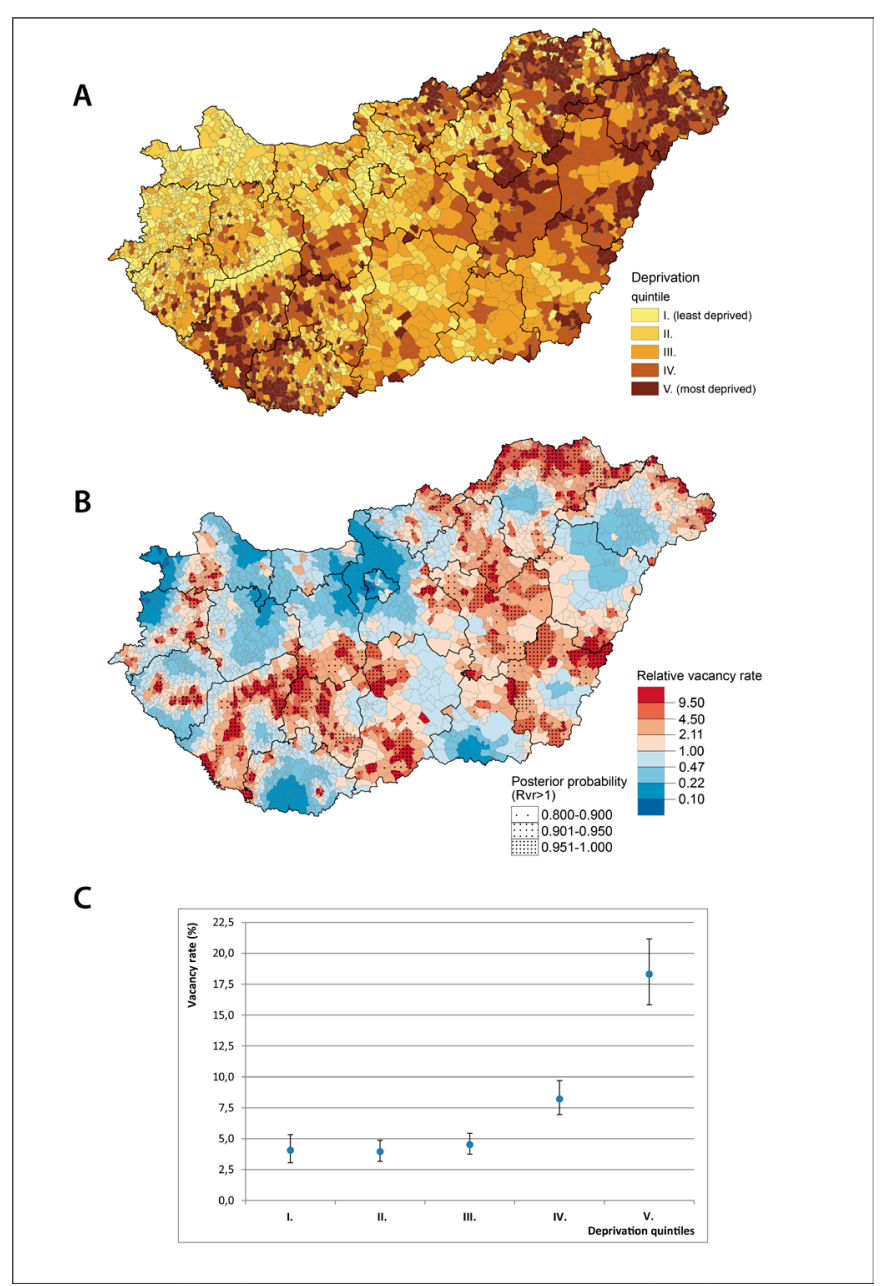

Figure 2 The distribution pattern of $(A)$ deprivation and of $(B)$ the relative vacancy rates in Hungary and $(C)$ the relationship between deprivation and the relative vacancy rate.

pattern of deprivation (figure 2C), as is verified by the results of association analysis for DI quintiles and practices with vacant GP posts. The results of the risk analysis showed an exponential association between relative vacancy rate and deprivation $\left(\chi^{2}\right.$ homogeneity $=232.18$, $\mathrm{p}<0.001, \chi^{2}$ linearity $\left.=168.87, \mathrm{p}<0.001\right)$.
Based on DI values, in the areas of highest deprivation (quintile V), nearly a fifth $(18.31 \%(15.83-21.16)$ ) of the practices had a vacancy for a GP; this rate is nearly triple that of the Hungarian average vacancy rate $(6.39 \%$ (5.88-6.94)). Even in quintile IV of the municipalities, $8.21 \%$ of the practices had vacant GP posts, that is, the vacancy rate exceeded the national average by $29 \%$. In the least deprived areas, the vacancy rate was $4.07 \%$, which was only $64 \%$ of the national average. The vacancy rates between the areas of deprivation quintiles, I, II and III, did not differ significantly (table 2 ).

\section{Moving GPs to another PC practice}

In the period examined, a definitive movement of GPs from the more deprived municipalities to the least deprived ones could be detected (table 3). In the least deprived (DI quintile I) areas, the number of GPs increased by $2.2 \%$, while in the most deprived areas (DI $\mathrm{V}$ ) it decreased by $8.4 \%$. Municipalities in the DI IV and V areas were losing GPs while those in DI I, II and III were gaining them. The resultant outcome of this trend is that the distribution of GPs, as well as the access to PC services by DI quintiles, became more inequitable (table 3 ).

\section{Change in rate of population underserved}

Parallel with the increasing vacancy rate, the rate of people with no PC service provision by their own GP was also increasing during the period examined in strong association with the deprivation. The rate of people (number of persons/100 000 people) with no PC service provision was increasing in time, especially in the most deprived quintile (table 4 ).

\section{DISCUSSION}

PC is considered to be the foundation of the healthcare system throughout the world. Currently, in countries with rapidly ageing populations and a high number of people living with chronic diseases, a strong and accessible base of PC providers is essential to the proper level of medical services as well to health promotion for the whole population. There is a general agreement in the scientific literature regarding a workforce crisis at the level of PC;

Table 2 Distribution of settlements with vacant general practitioner (GP) posts and the vacancy rates compared with the national average by deprivation index quintiles on 1 January 2017

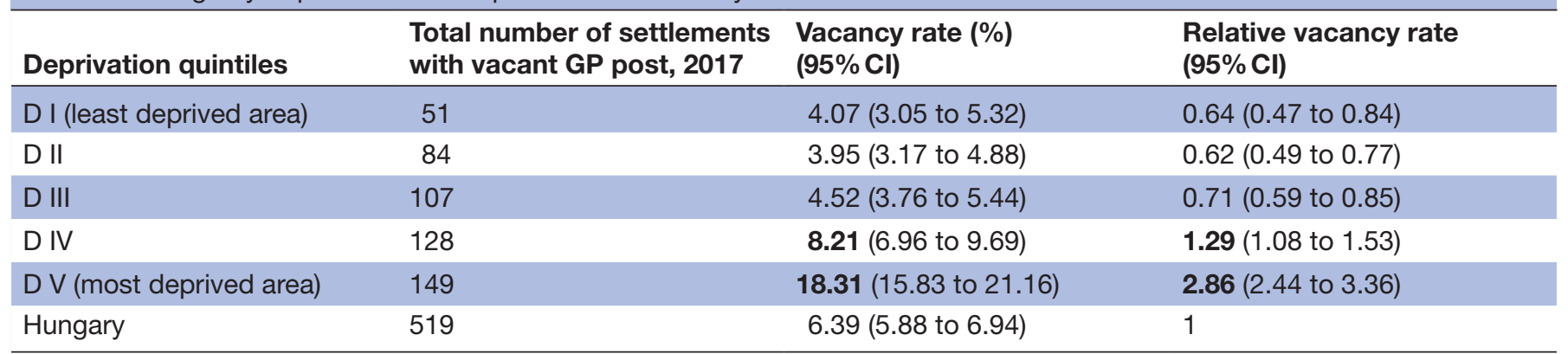

Bold values are of statistical significance. 
Table 3 Migration of general practitioners (GP) among areas with different deprivation statuses (DI-DV) between 1 January 2007 and 1 January 2017

\begin{tabular}{|c|c|c|c|c|c|}
\hline $\begin{array}{l}\text { Deprivation } \\
\text { quintiles }\end{array}$ & $\begin{array}{l}\text { Total number of } \\
\text { GPs, } 2017\end{array}$ & $\begin{array}{l}\text { Number of } \\
\text { outgoing GPs }\end{array}$ & $\begin{array}{l}\text { Number of } \\
\text { incoming GPs }\end{array}$ & $\begin{array}{l}\text { Gain/loss in } \\
\text { number of GPs }\end{array}$ & $\begin{array}{l}\text { Change between } 2007 \text { and } 2017 \\
(95 \% \mathrm{Cl})\end{array}$ \\
\hline DI & 809 & 53 & 71 & 18 & $2.22 \%(1.21$ to 3.24$)$ \\
\hline D II & 1802 & 98 & 118 & 20 & $1.11 \%(0.63$ to 1.59$)$ \\
\hline D III & 2029 & 120 & 142 & 22 & $1.08 \%(0.63$ to 1.53$)$ \\
\hline D IV & 1259 & 123 & 101 & -22 & $-1.75 \%(-1.02$ to -2.47$)$ \\
\hline D V & 451 & 93 & 55 & -38 & $-8.43 \%(-5.86$ to -10.99$)$ \\
\hline Total & 6350 & 487 & 487 & & \\
\hline
\end{tabular}

Bold values are of statistical significance.

the shortage of PC physicians now calls for attention and urgency worldwide. ${ }^{64}$

In our present report, the following trends and phenomena are clearly identified as characteristics of the Hungarian PC workforce crisis in the decade examined:

- Increasing number of PC practices with a vacant GP post.

- Decreasing number of GPs, especially in mixed and paediatric practices.

- Increasing average age of GPs in practice.

- Feminisation of the profession indicated by increasing representation of female GPs.

- Strong association between deprived areas and practices with unfilled posts for GP.
- Intense movement of GPs from the deprived areas to the least deprived ones.

It is evident that the GP shortage has a direct effect on the quality of PC service provision, but it is reasonable to suppose that it causes problems at the level of secondary care and in access to public health services. Although the usefulness and effectiveness of the gatekeeping function of GPs in reducing utilisation of emergency and hospital services are a subject of intense discussion with contradictory conclusions (see reviewed in 65 66) in the CEE countries with a very unfavourable health status of their population, ${ }^{6768}$ it seems to be essential. In these countries (except the Czech Republic and Slovakia), patients do not have direct access to hospital consultants, but the GPs

Table 4 Rate of underserved population by year and deprivation quintile

\begin{tabular}{|c|c|c|c|c|c|}
\hline \multirow[b]{2}{*}{ Year } & \multicolumn{5}{|c|}{ Underserved population per 100000 people $(95 \% \mathrm{CI})$} \\
\hline & D I & D II & D III & D IV & D V \\
\hline 2007 & $\begin{array}{l}581.09 \\
(571.21 \text { to } 591.11)\end{array}$ & $\begin{array}{l}1766.01 \\
\text { (1748.4 to } 1783.76)\end{array}$ & $\begin{array}{l}1724.06 \\
(1707.86 \text { to } 1740.38)\end{array}$ & $\begin{array}{l}3480.63 \\
\text { (3453.58 to } 3507.83)\end{array}$ & $\begin{array}{l}\mathbf{6 0 7 5 . 8 6} \\
(6035.00 \text { to } 6116.94)\end{array}$ \\
\hline 2008 & $\begin{array}{l}687.24 \\
(676.53 \text { to } 698.07)\end{array}$ & $\begin{array}{l}1465.92 \\
(1449.89 \text { to } 1482.09)\end{array}$ & $\begin{array}{l}1469.49 \\
(1454.53 \text { to } 1484.56)\end{array}$ & $\begin{array}{l}2690.60 \\
\text { (2666.76 to } 2714.60)\end{array}$ & $\begin{array}{l}6296.72 \\
\text { (6254.98 to } 6338.68)\end{array}$ \\
\hline 2009 & $\begin{array}{l}1066.93 \\
\text { (1053.62 to } 1080.36)\end{array}$ & $\begin{array}{l}1377.62 \\
(1362.07 \text { to } 1393.31)\end{array}$ & $\begin{array}{l}1258.64 \\
(1244.78 \text { to } 1272.61)\end{array}$ & $\begin{array}{l}2979.71 \\
\text { (2954.54 to } 3005.03)\end{array}$ & $\begin{array}{l}4893.96 \\
\text { (4857.04 to } 4931.09)\end{array}$ \\
\hline 2010 & $\begin{array}{l}1454.05 \\
(1438.55 \text { to } 1469.68)\end{array}$ & $\begin{array}{l}1205.07 \\
(1190.51 \text { to } 1219.77)\end{array}$ & $\begin{array}{l}1338.9 \\
(1324.58 \text { to } 1353.33)\end{array}$ & $\begin{array}{l}\mathbf{2 6 2 8 . 3 3} \\
\text { (2604.62 to } 2652.2 \text { ) }\end{array}$ & $\begin{array}{l}\mathbf{5 0 2 3 . 8 5} \\
(4986.32 \text { to } 5061.59)\end{array}$ \\
\hline 2011 & $\begin{array}{l}1029.26 \\
(1016.25 \text { to } 1042.40)\end{array}$ & $\begin{array}{l}\mathbf{2 1 6 0 . 0 0} \\
(2140.46 \text { to } 2179.66)\end{array}$ & $\begin{array}{l}1355.47 \\
\text { (1341.05 to } 1370.02)\end{array}$ & $\begin{array}{l}2931.45 \\
\text { (2906.32 to } 2956.75)\end{array}$ & $\begin{array}{l}5379.83 \\
\text { (5340.88 to } 5419.00)\end{array}$ \\
\hline 2012 & $\begin{array}{l}1348.85 \\
\text { (1333.96 to } 1363.86)\end{array}$ & $\begin{array}{l}\mathbf{1 7 7 9 . 9 2} \\
(1762.16 \text { to } 1797.80)\end{array}$ & $\begin{array}{l}1483.27 \\
(1468.15 \text { to } 1498.50)\end{array}$ & $\begin{array}{l}2929.17 \\
\text { (2903.97 to 2954.54) }\end{array}$ & $\begin{array}{l}6028.88 \\
(5987.54 \text { to } 6070.44)\end{array}$ \\
\hline 2015 & $\begin{array}{l}1397.14 \\
\text { (1382.05 to } 1412.36)\end{array}$ & $\begin{array}{l}\mathbf{2 1 6 0 . 6 4} \\
(2141.00 \text { to } 2180.41)\end{array}$ & $\begin{array}{l}2339.49 \\
(2320.44 \text { to } 2358.66)\end{array}$ & $\begin{array}{l}\mathbf{5 4 4 4 . 3 6} \\
\text { (5409.71 to } 5479.19)\end{array}$ & $\begin{array}{l}7303.19 \\
\text { (7257.56 to } 7349.03)\end{array}$ \\
\hline 2016 & $\begin{array}{l}\mathbf{2 1 4 5 . 7 8} \\
\text { (2127.10 to } 2164.59)\end{array}$ & $\begin{array}{l}2251.45 \\
\text { (2231.38 to } 2271.66 \text { ) }\end{array}$ & $\begin{array}{l}3072.88 \\
\text { (3051.00 to } 3094.88)\end{array}$ & $\begin{array}{l}\mathbf{6 1 1 6 . 5 9} \\
(6079.75 \text { to } 6153.61)\end{array}$ & $\begin{array}{l}\mathbf{7 1 8 6 . 5 3} \\
\text { (7141.19 to } 7232.08)\end{array}$ \\
\hline 2017 & $\begin{array}{l}1948.73 \\
(1930.92 \text { to } 1966.66)\end{array}$ & $\begin{array}{l}3331.61 \\
(3307.18 \text { to } 3356.18)\end{array}$ & $\begin{array}{l}3278.79 \\
(3256.18 \text { to } 3301.51)\end{array}$ & $\begin{array}{l}7057.39 \\
\text { (7017.81 to } 7097.14)\end{array}$ & $\begin{array}{l}8964.66 \\
\text { (8914.02 to } 9015.51)\end{array}$ \\
\hline
\end{tabular}

Bold values are of statistical significance. 
control access to secondary care. ${ }^{69}$ Although, currently, more outpatient specialist services can be approached in Hungary without referral, the traditional referral system is still the dominant one in practice. Consequently, the increasing number of practices with unfilled GP posts may strongly affect the health status of the populations not only by missing PC and preventive services, but through a backlog of referrals to relevant specialists, as well. It is worth mentioning that the population of the most deprived areas is the most affected by the GP shortage and the replacement of GPs in practices especially in small rural settlements is only partial, if any.

The chronic shortage of doctors in the primary healthcare sector owing to low pay, restricted opportunities for training or career progression and poor working conditions has been a well-known fact for a long time, ${ }^{70} 71$ but in the last decade, an exponential increase in vacant GP posts was observed in different countries. The Pulse magazine survey of 860 GPs in May 2017 found that $12.2 \%$ of positions were currently vacant in England, an increase from $2.1 \%$ in 2011 when Pulse started collecting these data. ${ }^{72}$ Similarly, in a survey in Scotland, $22 \%$ of responding PC practices reported current GP vacancies as of 31 August 2015, an increase from 9\% of practices reporting current vacancies in $2013 .^{73}$ The same phenomenon can be detected in Hungary, where the number of PC practices with an unfilled GP post almost tripled in the period of 2010-2017. The decrease is significant in the number of GPs in all types of practices, but it is more pronounced in mixed and paediatric practices. It seems that the mixed general practices are less attractive among GPs. One of the possible reasons of this phenomenon is that most of these practices are found in small settlements where the GP is the only PC service provider. The reason of the decrease in the number of paediatricians is also clear; the paediatrician medical specialisation training focuses mostly on the hospital replacement in Hungary. Hospitals in many parts of the country are currently reporting shortages in paediatricians and young medical graduates take the hospital work more attractive and the carrier paths more clear at present.

Parallel with the decrease in the number of GPs, the average age of the GPs became significantly higher. The age distribution clearly indicates that the number of male GPs under the age of 60 years was lower in 2017 than in 2007 across all ages, while in the case of female GPs, although the trend is very similar, increases can be seen at certain ages, mainly at younger ones. This fact is in harmony with the observed feminisation of the profession. In a systematic review based on 32 relevant publications to examine the evidence that quantifies the effect of feminisation on practice characteristics, Hedden and her colleagues ${ }^{74}$ note "that female GPs self-report fewer hours of work than male GPs, have fewer patient encounters, and deliver fewer services, but spend longer with their patients during a contact and address more separate presenting problems in one visit', and conclude that 'the feminization of the workforce is likely to have a small negative impact on the availability of primary health care services, and the drivers of observed differences between male and female GPs are complex and nuanced'. Considering the fact that Hungary is among the 10 countries that have the best parental leave policies in the worldthe length of paid maternity leave is 24 weeks and is paid at $70 \%$ of salary, which can be extended by an additional time off paid at $40 \%$ of salary for 136 weeks $^{75}$-female doctors may stay away from work for a fairly long time, which can make finding a suitable temporary replacement problematic.

Behind the fact that in Hungarian PC there is a strong association between deprived areas and practices with unfilled posts for GPs and the intense movement of GPs from the deprived areas to the least deprived ones is the probability of an existing financial background. Although the majority of GPs are private entrepreneurs, capitation-based financing is almost exclusively based on the list size of the practices, and only approximately 3\% of GPs' reimbursement is pay for performance. Consequently, GPs are financially motivated to maximise the number of persons in the practice and minimise performance. ${ }^{39}$ According to the estimated data from the Hungarian Medial Chamber, in 2017, after covering the expenses related to maintaining the infrastructure and salaries of the other health staff (at least a nurse) the remaining income that can be used to pay the salary of the GP was approximately $€ 1000$ before taxation. Although it can be-and should be-refused on the basis of ethical considerations, it remains a fact that the informal so-called 'gratuity' payment from the patients for GP services is more or less essential to make a living. It is reasonable to suppose that moving GPs from deprived areas to least deprived ones is-at least in partmotivated by the expected increase in 'gratuity' payment. These observations clearly indicate that targeted intervention from the Ministry of Human Capacities is needed to provide the NIHIFM with decision-making responsibility and financing opportunities to support effective recruitment and retention of GPs for the most deprived areas, and for the Hungarian PC system as a whole, as well.

The recruitment and retention problems are well known in the PC systems of developed countries, but information about effective strategies and interventions is very limited. Recently, a systematic review was undertaken in which 51 studies assessing 42 interventions categorised into 13 groups (financial incentives, recruiting rural students, international recruitment, rural-focused or primary-care-focused undergraduate placements, rural or underserved postgraduate training, well-being or peer support initiatives, marketing, mixed interventions, support for professional development or research, retainer schemes, re-entry schemes, specialised recruiters or case managers and delayed partnerships) were retrieved. Weak evidence supported the use of postgraduate placements in underserved areas, undergraduate rural placements and recruiting students to medical school from rural areas, and there was mixed evidence about financial incentives. ${ }^{76}$ 
A single report on a longitudinal small area whole country study using lower super output area data and the Index of Multiple Deprivation 2010 rankings for England described substantial inequalities in GPs' service, expressed in full-time equivalent (FTE) GPs before the EAPMC programme was launched in December 2007. EMPMC invested $£ 250$ million towards establishing new general practices and GP-led health centres, as well as towards extending opening hours and expanding services in the 38 most underdoctored primary care trust areas and providing a guaranteed competitive salaries for GPs. Total numbers of FTE for GPs have grown much faster in the most deprived fifth of small areas in England than elsewhere, with the GP supply in the most affluent fifth growing at the slowest pace over the 10 years covered by the study. ${ }^{16}$ Our findings obtained in our longitudinal study strongly differ from the results presented as outcomes of the EAMC programme. It is reasonable to suppose that the main cause of the difference that competitive salaries for GPs are not guaranteed in Hungary. According to OECD figures, the income of a GP in Denmark is five times larger than the income of a GP in Hungary, and the average GP in Scandinavia earns 5-10 times more than the average GP in Hungary. ${ }^{77}$ In 2013, a salary increase programme for GPs started in Hungary, but the annual growth rate in nominal terms was as low as $2.3 \%{ }^{78}$ However, since 2014, a single settlement allowance has been given to GPs at the time of entering into a permanently vacant GP posts; no permanent incentives were introduced to support movement by GPs into underserved deprived areas. Although studies on the effect of financial incentives for GPs in Hungary are lacking, it can be stated that without increasing the salaries of GPs there is no chance to stop the deepening workforce crisis in Hungarian PC.

The limitation of our study is that it is an ecological one that assumes that individual members of a group all have the average characteristics of the group as whole, when, in fact, any association observed between variables at the group level does not necessarily mean that the same association exists for an individual plucked from the group. In addition, we had no opportunity to study the effects of different healthcare reforms on the PC workforce in Hungary.

Contributors MP, JS, CN, AJ and RA developed the study design. LK identified the practices by location, vacancy and characteristics of GPs. MP, AJ and CN did the data processing and analyses. MP wrote the first draft of the paper and RA finalised it. All authors critically revised the first draft and approved the final manuscript submitted for publication.

Funding This work was supported by the Swiss Contribution SH/8/1 project and by the GINOP-2.3.2-15-2016-00005 project financed by the European Union under the European Social Fund and European Regional Development Fund, as well as by the Hungarian Academy of Sciences (TK2016-78).

Map disclaimer The depiction of boundaries on the map(s) in this article do not imply the expression of any opinion whatsoever on the part of BMJ (or any member of its group) concerning the legal status of any country, territory, jurisdiction or area or of its authorities. The map(s) are provided without any warranty of any kind, either express or implied.

Competing interests None declared.
Patient consent for publication Not required.

Provenance and peer review Not commissioned; externally peer reviewed.

Data sharing statement Data were provided by the National Institute of Health Insurance Fund Management, the Regional Informational System of the Ministry of Local Government and Regional Development, the Hungarian Central Statistical Office and the Hungarian Tax and Financial Control Administration. Data requests should be sent to Roza Adany.

Open access This is an open access article distributed in accordance with the Creative Commons Attribution Non Commercial (CC BY-NC 4.0) license, which permits others to distribute, remix, adapt, build upon this work non-commercially, and license their derivative works on different terms, provided the original work is properly cited, appropriate credit is given, any changes made indicated, and the use is non-commercial. See: http://creativecommons.org/licenses/by-nc/4.0/.

\section{REFERENCES}

1. Campbell J, Dussault G, Buchan J, et al. A universal truth: no health without a workforce. Forum report, Third Global Forum on Human Resources for Health, Recife, Brazil. Geneva: World Health Organization, 2013.

2. Hays R, Pong LT, Leopando Z, et al. Primary care in the Asia-Pacific region: challenges and solutions. Asia Pac Fam Med 2012;11:8.

3. Strasser R, Kam SM, Regalado SM. Rural health care access and policy in developing countries. Annu Rev Public Health 2016;37:395-412.

4. Berwick DM, Hackbarth AD. Eliminating waste in US health care. JAMA 2012;307:1513-6.

5. Petterson SM, Liaw WR, Tran C, et al. Estimating the residency expansion required to avoid projected primary care physician shortages by 2035. Ann Fam Med 2015;13:107-14.

6. Dale J, Potter R, Owen K, et al. Retaining the general practitioner workforce in England: what matters to GPs? A cross-sectional study. BMC Fam Pract 2015;16:140.

7. Hayhoe B, Majeed A, Hamlyn M, et al. Primary care workforce crisis: how many more GPs do we need? Harrogate: RCGP Annual Conference, 2016.

8. Majeed A. Shortage of general practitioners in the NHS. BMJ 2017;358:j3191.

9. Burla L, Widmer M. Le corps médical en Suisse: effectif et évolutions jusqu'en 2011. 2012 https://www.obsan.admin.ch/sites/default/files/ publications/2015/obsan_bulletin_2012-03_f.pdf (Accessed Feb 2019).

10. Seematter-Bagnoud L, Junod J, Jaccard Ruedin H, et al. Offre et recours aux soins médicaux ambulatoires en Suisse - Projections à l'horizon 2030. Neuchâtel: Observatoire suisse de la santé. 2008 https://www.obsan.admin.ch/sites/default/files/publications/2015/ arbeitsdokument-33.pdf (Accessed Feb 2019).

11. OECD Publishing, Paris. OECD/EU (2016), Health at a Glance: Europe 2016: State of Health in the EU Cycle. http://dx.doi.org/10. 1787/9789264265592-en.

12. Comino EJ, Davies GP, Krastev Y, et al. A systematic review of interventions to enhance access to best practice primary health care for chronic disease management, prevention and episodic care. BMC Health Serv Res 2012;12:415.

13. Irish Medical Association. IMO position paper on health inequalities. 2012 https://www.imo.ie/policy-international-affair/overview/IMOPosition-Paper-on-Health-Inequalities.pdf (Accessed Feb 2019).

14. Bauer J, Brueggmann D, Ohlendorf D, et al. General practitioners in German metropolitan areas - distribution patterns and their relationship with area level measures of the socioeconomic status. BMC Health Serv Res 2016;16:672.

15. Baker M, Ware J, Morgan K. Time to put patients first by investing in general practice. Br J Gen Pract 2014;64:268-9.

16. Asaria M, Cookson R, Fleetcroft R, et al. Unequal socioeconomic distribution of the primary care workforce: whole-population small area longitudinal study. BMJ Open 2016;6:e008783.

17. Steinhaeuser J, Otto P, Goetz K, et al. Rural area in a European country from a health care point of view: an adoption of the Rural Ranking Scale. BMC Health Serv Res 2014;14:147.

18. Kringos D, Boerma W, Hutchinson A, et al. Building primary care in a changing Europe. 38th edn. Copenhagen, 2015.

19. Yardim M, ner S. Geographical disparities in the distribution of physicians in Turkey. TAF Prev Med Bull 2013;12:487-94.

20. Matsumoto M, Inoue K, Farmer J, et al. Geographic distribution of primary care physicians in Japan and Britain. Health Place 2010;16:164-6. 
21. Petterson SM, Phillips RL, Bazemore AW, et al. Unequal distribution of the US primary care workforce. Am Fam Physician 2013;11.

22. Hann M, Gravelle $H$. The maldistribution of general practitioners in England and Wales: 1974-2003. Br Gen Pract 2004;54:894-8.

23. Isabel C, Paula V. Geographic distribution of physicians in Portugal. Eur J Health Econ 2010;11:383-93.

24. Fülöp $\mathrm{G}$, Kopetsch $\mathrm{T}$, Hofstätter $\mathrm{G}$, et al. Regional distribution effects of 'needs planning' for office-based physicians in Germany and Austria-methods and empirical findings. J Public Health 2008;16:447-55.

25. Brown MC. Using Gini-style indices to evaluate the spatial patterns of health practitioners: theoretical considerations and an application based on Alberta data. Soc Sci Med 1994;38:1243-56.

26. Stapleton G, Schröder-Bäck $P$, Brand $\mathrm{H}$, et al. Health inequalities and regional specific scarcity in primary care physicians: ethical issues and criteria. Int J Public Health 2014;59:449-55.

27. World Health Organization. The world health report - primary health care (now more than ever). 2008 https://www.who.int/whr/2008/en/ (Accessed Feb 2019).

28. World Health Organization. Increasing access to health workers in remote and rural areas through improved retention. Background paper. Geneva. 2009 https://www.who.int/hrh/retention/guidelines/ en/ (Accessed Feb 2019).

29. Watson J, Humphrey A, Peters-Klimm F, et al. Motivation and satisfaction in GP training: a UK cross-sectional survey. $\mathrm{Br} J$ Gen Pract 2011;61:e645-9.

30. Fletcher E, Abel GA, Anderson R, et al. Quitting patient care and career break intentions among general practitioners in South West England: findings of a census survey of general practitioners. BMJ Open 2017;7:e015853

31. Blane DN, McLean G, Watt G. Distribution of GPs in Scotland by age, gender and deprivation. Scott Med J 2015;60:214-9.

32. Iacobucci G. GPs in Northern Ireland face "full blown crisis," BMA warns. BMJ 2016;353:i3202.

33. Zieler P. [Physician shortage in Saxony-Anhalt. The former youngster returns as country doctor]. MMW Fortschr Med 2015;157:36-7.

34. Schmidt S, Gresser U. [Development and consequences of physician shortages in Bavaria]. Versicherungsmedizin 2014;66:25-9.

35. Roeger LS, Reed RL, Smith BP. Equity of access in the spatial distribution of GPs within an Australian metropolitan city. Aust J Prim Health 2010;16:284-90.

36. Ádány R, Kósa K, Sándor J, et al. General practitioners' cluster: a model to reorient primary health care to public health services. Eur $J$ Public Health 2013;23:529-30.

37. Sándor J, Kósa K, Fürjes G, et al. Public health services provided in the framework of general practitioners' clusters. Eur J Public Health 2013;23:530-2.

38. Kósa K, Sándor J, Dobos É, et al. Human resources development for the operation of general practitioners' cluster. Eur J Public Health 2013;23:532-3.

39. Sándor J, Kósa K, Papp M, et al. Capitation-based financing hampers the provision of preventive services in primary health care. Front Public Health 2016;4:200.

40. Lember M, Cartier T, Bourgueil Y. Structure and organization of primary care. In: Kringos DS, Boerma WGW, Hutchinson A, eds. Building primary care in a changing Europe, Observatory Studies Series, No. 38, 2015:41-9.

41. Juhász A, Nagy C, Páldy A, et al. Development of a Deprivation Index and its relation to premature mortality due to diseases of the circulatory system in Hungary, 1998-2004. Soc Sci Med 2010;70:1342-9.

42. Nagy C, Juhász A, Beale L, et al. Mortality amenable to health care and its relation to socio-economic status in Hungary, 2004-08. Eur $J$ Public Health 2012;22:620-4.

43. Nagy C, Juhász A, Papp Z, et al. Hierarchical spatio-temporal mapping of premature mortality due to alcoholic liver disease in Hungary, 2005-2010. Eur J Public Health 2014;24:827-33.

44. Boruzs K, Juhász A, Nagy $\mathrm{C}$, et al. Relationship between statin utilization and socioeconomic deprivation in hungary. Front Pharmacol 2016;7:66.

45. Zs J, Juhasz A, Nagy C, et al. Trends and territorial inequalities of incidence and survival of childhood leukaemia and their relations to socioeconomic status in Hungary, 1971-2015. Eur J Cancer Prev 2017;1.

46. Fairburn J, Maier W, Braubach M. Incorporating environmental justice into second generation indices of multiple deprivation: lessons from the UK and Progress Internationally. Int J Environ Res Public Health 2016;13:750.

47. Department for Communities and Local Government. English indices of deprivation. $2015 \mathrm{http}: / /$ www.gov.uk/government/statistics/ english-indices-of-deprivation-2015 (Accessed Feb 2019).
48. Scottish Index of Multiple Deprivation. The Scottish government scottish index of multiple deprivation. http://www.gov.scot/Topics/ Statistics/SIMD (Accessed Feb 2019).

49. Welsh Government. Welsh index of multiple deprivation (WIMD) http://gov.wales/statistics-and-research/welsh-index-multipledeprivation/?lang=en (Accessed Feb 2019).

50. Northern Ireland. Multiple deprivation measure 2017 (NIMDM2017). https://www.nisra.gov.uk/statistics/deprivation/northern-irelandmultiple-deprivation-measure-2017-nimdm2017 (Accessed Feb 2019).

51. Havard S, Deguen S, Bodin J, et al. A small-area index of socioeconomic deprivation to capture health inequalities in France. Soc Sci Med 2008;67:2007-16.

52. Sánchez-Cantalejo $C$, Ocana-Riola R, Fernández-Ajuria A Deprivation index for small areas in Spain. Soc Indic Res 2008;89:259-73.

53. Domínguez-Berjón MF, Borrell C, Cano-Serral G, et al. [Constructing a deprivation index based on census data in large Spanish cities(the MEDEA project)]. Gac Sanit 2008;22:179-87.

54. Kroll LE, Schumann M, Hoebel J, et al. Regional health differences developing a socioeconomic deprivation index for Germany. Journal of Health Monitoring 2017

55. Meijer M, Engholm G, Grittner U, et al. A socioeconomic deprivation index for small areas in Denmark. Scand J Public Health 2013;41:560-9.

56. Panczak R, Galobardes B, Voorpostel M, et al. A Swiss neighbourhood index of socioeconomic position: development and association with mortality. $J$ Epidemiol Community Health 2012;66:1129-36.

57. Caranci N, Biggeri A, Grisotto L, et al. L'indice di deprivazione italiano a livello di sezione di censimento: definizione, descrizione e associazione con la mortalit. Epidemiol Prev 2010;34:167-76.

58. Slachtová $\mathrm{H}$, Tomásková $\mathrm{H}$, Splíchalová $\mathrm{A}$, et al. Czech socioeconomic deprivation index and its correlation with mortality data. Int $J$ Public Health 2009;54:267-73.

59. Zadnik V, Guillaume E, Lokar K, et al. Slovenian version of the european deprivation index at municipal level. Zdr Varst 2018;57:47-54

60. Besag J, York J, Molli A. Bayesian image restoration, with two applications in spatial statistics. Ann Inst Stat Math 1991;43:1-20.

61. R Development Core Team. R: A Language and Environment for Statistical Computing, R Foundation for Statistical Computing, Vienna, Austria. 2017 www.R-project.org (Accessed Feb 2019).

62. Rue H, Martino S, Chopin N. Approximate Bayesian inference for latent Gaussian models using integrated nested Laplace approximations (with discussion). Journal of the Royal Statistical Society, Series B 2009;2:319-92.

63. Beale L, Hodgson S, Abellan JJ, et al. Evaluation of spatial relationships between health and the environment: the rapid inquiry facility. Environ Health Perspect 2010;118:1306-12.

64. Song Z, Chopra V, McMahon LF. Addressing the primary care workforce crisis. Am J Manag Care 2015;8:e452-4.

65. Van den Heede K, Van de Voorde C. Interventions to reduce emergency department utilisation: a review of reviews. Health Policy 2016;120:1337-49.

66. Greenfield G, Foley K, Majeed A. Rethinking primary care's gatekeeper role. BMJ 2016;354:4803.

67. Karanikolos M, Adany R, McKee M. The epidemiological transition in Eastern and Western Europe: a historic natural experiment. Eur Public Health 2017;27(suppl_4):4-8.

68. Mackenbach JP. Nordic paradox, Southern miracle, Eastern disaster: persistence of inequalities in mortality in Europe. Eur $J$ Public Health 2017;27(suppl_4):14-17.

69. Health Consumer Powerhouse Ltd. Euro health consumer index 2016. 2017 https://healthpowerhouse.com/media/EHCl-2016/EHCl2016-report.pdf (Accessed Feb 2019).

70. Rechel B, Dubois C-A, McKee M. The Health Care Workforce in Europe Learning from experience. European Observatory on Health Systems and Policies. 2006 http://www.euro.who.int/_data/assets/ pdf file/0008/91475/E89156.pdf (Accessed Feb 2019).

71. Kuehn BM. Reports warn of primary care shortages. JAMA 2008;300:1872-5.

72. NHS Provider. Summary of vacancy shortfall and fill rate data for the clinical workforce. $2017 \mathrm{https} / / / \mathrm{nhsproviders.org/media/3903/}$ summary-of-vacancy-shortfall-and-fill-rate-data-for-the-clinicalworkforce.pdf (Accessed Feb 2019).

73. National Services Scotland, Information Services Division, Publication Report. Primary Care Workforce Survey Scotland 2015, A Survey of Scottish General Practices and General Practice Out of Hours Services. $2016 \mathrm{http}: / /$ www.isdscotland.org/Health-Topics/ General-Practice/Publications/2016-06-14/2016-06-14-PrimaryC 
areWorkforceSurveyScotland2015-Report.pdf (Accessed Feb 2019).

74. Hedden L, Barer ML, Cardiff K, et al. The implications of the feminization of the primary care physician workforce on service supply: a systematic review. Hum Resour Health 2014;12:32.

75. Weller $C$. These 10 countries have the best parental leave policies in the world. $2016 \mathrm{https}: / /$ www.weforum.org/agenda/2016/08/these- 10-countries-have-the-best-parental-leave-policies-in-the-world (Accessed 28 Feb 2019).

76. Verma P, Ford JA, Stuart A, et al. A systematic review of strategies to recruit and retain primary care doctors. BMC Health Serv Res 2016;16:126.

77. OECD health statistics. 2017.

78. OECD health statistics. 2015 